\title{
ББК65.05
}

\section{АНАЛИЗ ПРОЦЕССОВ ИНТЕЛЛЕКТУАЛИЗАЦИИ В СТРАНАХ БРИКС}

\author{
(c) 2020 Горлачева Евгения Николаевна \\ МГТУ им. Н. Э. Баумана, Россия, Москва \\ (c) 2020 Тихомирова Татьяна Владимировна \\ студент, кафедра «Промышленная логистика» \\ МГТУ им. Н. Э. Баумана, Россия, Москва
}

кандидат экономических наук, доцент, кафедра «Промышленная логистика»

В статье предложен инструмент измерения процессов интеллектуализации в странах БРИКС индекс когнитивности. Проведенные расчеты показывают, что страны БРИКС находятся в переходном состоянии и усиление государственных программ, направленных на формирование когнитивной экономики, дает им шанс преодолеть нарастающее отставание с развитыми странами.

Ключевые слова: когнитивная экономика, страны БРИКС, индекс когнитивности, интеллектуализация, экономический рост, интеллектуальные ресурсы, инновационное развитие, эконометрические методы

Актуальность исследуемых в работе проблем определяется глобальным влиянием стран БРИКС в современном мире. Несмотря на обширные территории, богатейшие природные богатства, многочисленное население, экономический рост в странах БРИКС стал ощутимо замедляться [4]. В настоящее время тенденция замедления экономического роста стран БРИКС углубляется, а две из них - Россия и Бразилия находятся в состоянии глубокой экономической рецессии.

Принципиальной особенностью текущего периода развития мировой экономики выступает качественная трансформация ее технологического базиса, формирующие глобальные вызовы для будущего мирового социальноэкономического развития. Качественное изменение материального производства приводит к формированию нового качества экономики и общества, и последующего формирования качественно иного способа хозяйственной деятельности человека - когнитивной экономики [13, 14].

Исследование состояния когнитивной экономики относительно ново для стран БРИКС. Целью настоящей статьи является разработка методологического инструмента, позволяющего оценивать состояние когнитивной экономики в странах БРИКС. Достижение поставленной цели обусловлено решением ряда задач: анализ инструментов, позволяющих оценить процессы интеллектуализации в экономике; разработка индекса когнитивности, моделирование и интерпретация полученных результатов.

Статья структурирована следующим образом: во второй части рассмотрены проблемы когнитивной экономики в странах БРИКС, в третьей части проведен анализ методологических инструментов мониторинга процессов интеллектуализации и представлен разработанный инструмент - индекс когнитивности; в четвертой части проведены расчеты индекса по странам БРИКС, описаны полученные результаты и дана их экономическая интерпретация; в заключительной части - представлены выводы проведенного исследования.

Анализ состояния когнитивной экономики в странах БРИКС

Когнитивная экономика предполагает инновационный путь развития, основанный на новых знаниях, технологиях, конкурентоспособных и эффективных предприятиях. Одним из показателей инновационной активности в экономике являются затраты на исследования и разработки. Они приведены в таблице 1 в миллионах долларов, текущих ценах и пересчитанные по паритету покупательной способности для стран БРИКС.

Таким образом, по внутренним затратам на исследования и разработки Россия уступает не только развитым странам-лидерам, но и некоторым быстрорастущим экономикам, входящим в группу БРИКС. Среди представленных стран явными лидерами по величине затрат (Рис. 1) оказались США, страны Евросоюза и Китай. Россия 
Таблица 1. Внутренние затраты на исследования и разработки стран БРИКС

\begin{tabular}{|l|l|c|c|c|c|}
\hline \multirow{2}{*}{ Название страны } & $\begin{array}{c}\text { Абсолютное } \\
\text { значение/ } \\
\text { \% от ВВП }\end{array}$ & 2005 & 2014 & 2016 & 2018 \\
\hline \multirow{2}{*}{ Китай } & млн. долларов & 86639,8 & 372326,1 & 453054,8 & 554327,8 \\
\hline \multirow{2}{*}{ Россия } & \% от ВВП & 1,31 & 2,03 & 2,12 & 2,19 \\
\hline \multirow{2}{*}{ Бразилия } & млн. долларов & 18120,5 & 40330,2 & 39008,6 & 41505,1 \\
\cline { 2 - 6 } & \% от ВВП & 0,99 & 1,07 & 1,10 & 0,99 \\
\hline \multirow{2}{*}{ Индия } & млн. долларов & 16771,8 & 31192,6 & 23698,9 & 25962,7 \\
\cline { 2 - 6 } & \% от ВВП & 0,82 & 1,27 & 1,32 & 1,39 \\
\hline \multirow{2}{*}{ ЮАР } & млн. долларов & 7336,3 & 14885,6 & 15570,3 & 16856,1 \\
\cline { 2 - 6 } & \% от ВВП & 0,36 & 0,73 & 0,68 & 0,62 \\
\hline \multirow{2}{*}{ Страны Евросоюза } & млн. долларов & 4619,6 & 5297,8 & 5714,5 & 5871,5 \\
\cline { 2 - 6 } & \% от ВВП & 0,86 & 0,76 & 0,81 & 0,78 \\
\hline \multirow{2}{*}{ США } & \%лн. долларов & 226913,5 & 371249,2 & 406755,1 & 464466,4 \\
\hline
\end{tabular}

Источник: составлено автором по данным [2,16].

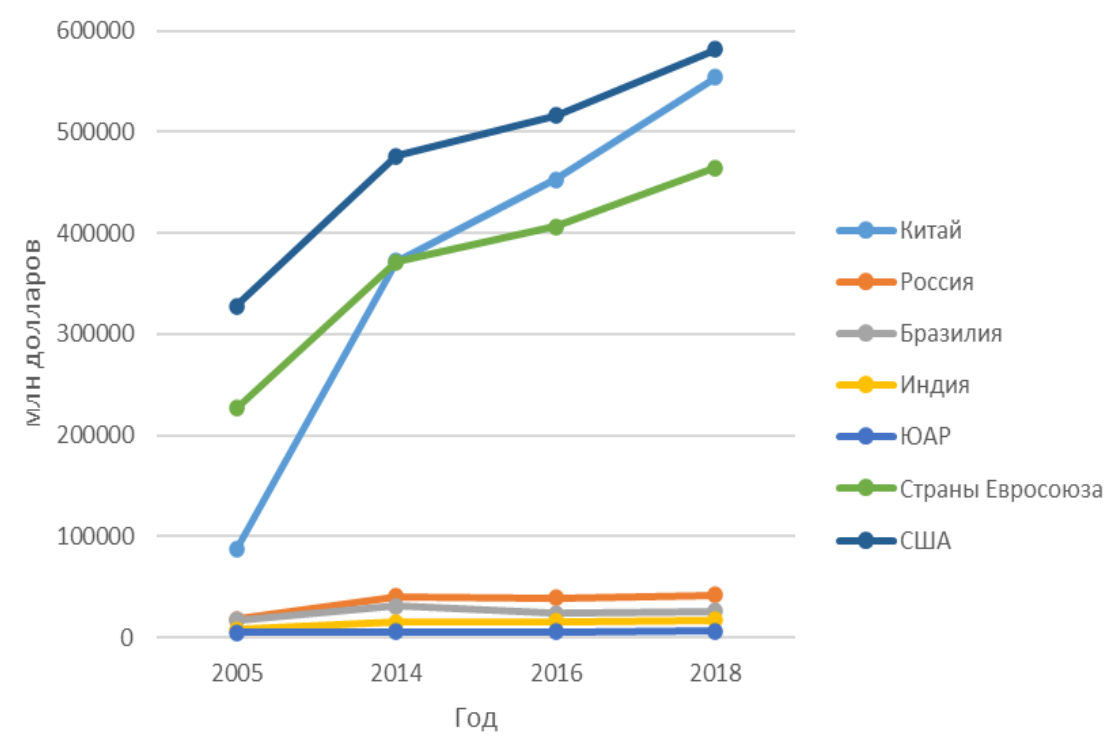

Рисунок 1. График внутренних затрат на исследования и разработки в миллионах долларов

здесь на 4 месте, опережает Бразилию, Индию и ЮАР. Наименьшая величина затрат, в ЮАР, равна 5871,5 млн. долларов в 2018 году, что в 99 раз меньше, чем в США (581553 млн. долларов в 2018 году).

По доли внутренних затрат на исследования и разработки (рис. 2) Россия уступает также и Бразилии. Абсолютным лидером является США (2,83\% от ВВП в 2018 году), а отстает от всех стран Индия (0,62\% от ВВП в 2018 году) [6-9].

Перспективным направлением сотрудничества стран БРИКС в сфере когнитивной эконо- мики представляется развитие диалога, обмена наилучшими практиками, информацией и опыTOM.

Анализ инструментов мониторинга процессов интеллектуализации

Распространение цифровых технологий, повышение требований к когнитивным способностям затрудняет не только концептуализацию когнитивной экономики, но измерение ее масштабов. В настоящее время используют различные методики и подходы для измерения процессов интеллектуализации (Табл. 2) [1]. 


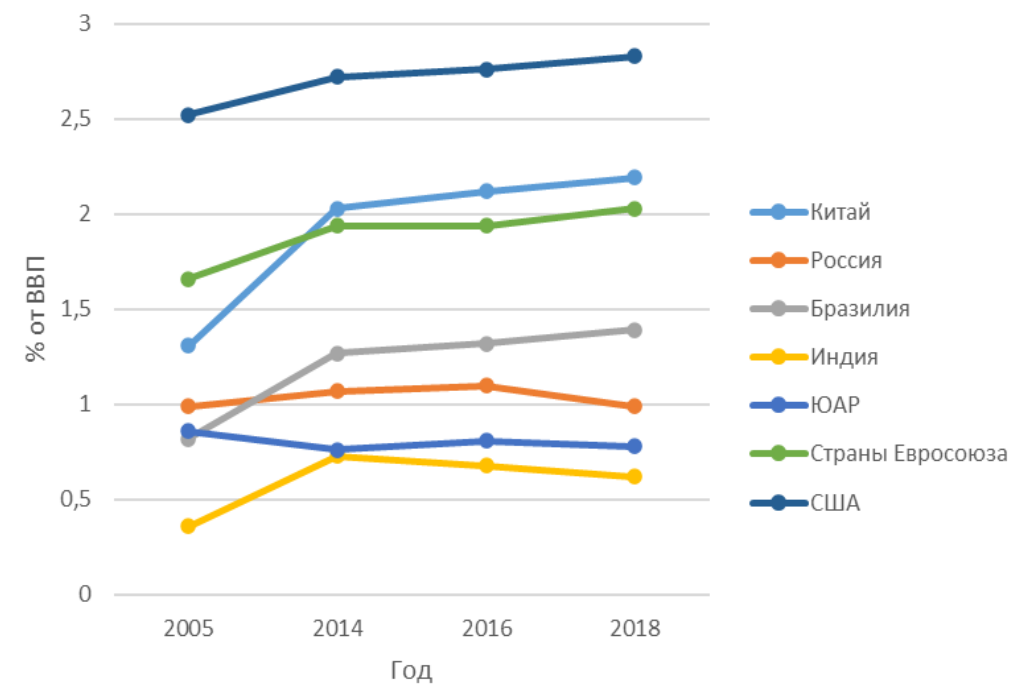

Рисунок 2. График внутренних затрат на исследования и разработки в процентах от ВВП

Таблица 2. Совокупность аналитических инструментов мониторинга интеллектуализации

\begin{tabular}{|c|c|c|c|}
\hline №№ & Наименование инструмента & Содержание & $\begin{array}{c}\text { Наименование организации- } \\
\text { разработчика }\end{array}$ \\
\hline 1 & Индекс конкурентоспособности & $\begin{array}{l}\text { Способность страны в усло- } \\
\text { виях конкуренции произво- } \\
\text { дить блага, удовлетворяющие } \\
\text { требованиям мирового рынка } \\
\text { и повышающие благосостояние } \\
\text { народа }\end{array}$ & $\begin{array}{l}\text { Всемирный экономический } \\
\text { форум/ Международный инсти- } \\
\text { тут менеджмента и развития } \\
\text { (г. Лозанна) }\end{array}$ \\
\hline 2 & $\begin{array}{l}\text { Индекс технологических дости- } \\
\text { жений }\end{array}$ & $\begin{array}{l}\text { Предназначен для оценки } \\
\text { уровня развития страны в части } \\
\text { создания и распространения } \\
\text { технологий, а также формиро- } \\
\text { вания навыков человека }\end{array}$ & $\begin{array}{l}\text { Программа развития ООН } \\
\text { (ПРООН) }\end{array}$ \\
\hline 3 & Глобальный индекс инноваций & $\begin{array}{l}\text { Предназначен для оценки } \\
\text { инновационного развития и } \\
\text { условий его воплощения }\end{array}$ & INSEAD, Франция \\
\hline 4 & Индекс экономики знаний & $\begin{array}{l}\text { Предназначен для оценки, } \\
\text { характеризующий уровень эко- } \\
\text { номики, основанной на знаниях }\end{array}$ & Всемирный банк \\
\hline
\end{tabular}

Представляется, что способы и подходы к конструированию индекса могут быть существенно расширены за счет использования эконометрических методов [15]. Для конструирования индекса когнитивности был выбран следующий перечень показателей (см. Таблицу 3).

Выбранные показатели охватывают все принципиально важные процессы когнитивной экономики [3, 10, 12]. Среди них показатели человеческого капитала, ресурсного обеспечения инноваций и распространения ИКТ. Схема агрегации индекса когнитивности представлена на рис. 3.

В качестве инструмента использовалась методология STATIS [15]. Методология STATIS - это исследовательский метод многомерного анализа данных, основанный на линейной алгебре и евклидовых векторных пространствах. Эта методология позволяет проанализировать наличие общей структуры в нескольких таблицах данных, полученных с течением времени, выявить различия и сходства в течение исследуемого периода. Все исходные данные были центрированы и уменьшены, потому что переменные неоднородны, в разных единицах измерения. Были вы- 
Таблица 3. Система показателей индекса когнитивности

\begin{tabular}{|c|c|c|}
\hline № & Наименование показателя & Ед. изм. \\
\hline \multicolumn{3}{|c|}{ Субиндекс 1 «Человеческий капитал и информационная грамотность» } \\
\hline$x_{1}$ & $\begin{array}{l}\text { Доля занятого населения в возрасте 25-64 лет, имеющего высшее образование в } \\
\text { общей численности занятого населения соответствующей возрастной группы }\end{array}$ & процент \\
\hline$x_{2}$ & Уровень грамотности взрослого населения & процент \\
\hline$x_{3}$ & $\begin{array}{l}\text { Удельный вес обучающихся общеобразовательных учреждений и общей численно- } \\
\text { сти населения }\end{array}$ & процент \\
\hline$x_{4}$ & $\begin{array}{l}\text { Удельный вес студентов, обучающихся по образовательным программам высше- } \\
\text { го образования (программ бакалавриата, магистратуры, специалитета) в общей } \\
\text { численности населения }\end{array}$ & процент \\
\hline \multicolumn{3}{|c|}{ Субиндекс 2 «Ресурсная база для осуществления инноваций» } \\
\hline$x_{5}$ & Доля внутренних затрат на исследования и разработки, в\% к ВВП & процент \\
\hline$x_{6}$ & $\begin{array}{l}\text { Доля внутренних затрат на научные исследования и разработки сектора ИКТ, в } \\
\text { общем объеме внутренних затрат на научные исследования и разработки }\end{array}$ & процент \\
\hline$x_{7}$ & $\begin{array}{l}\text { Доля затрат на технологические инновации, в общем объеме отгруженных товаров, } \\
\text { выполненных работ, услуг организаций промышленного производства и сферы } \\
\text { услуг }\end{array}$ & процент \\
\hline$x_{8}$ & $\begin{array}{l}\text { Удельный вес затрат на исследования и разработки, нацеленные на развитие эко- } \\
\text { номики, в общем объеме внутренних затрат на исследование и разработки }\end{array}$ & процент \\
\hline$x_{9}$ & $\begin{array}{l}\text { Доля организаций, промышленного производства и сферы услуг, осуществлявших } \\
\text { технологические инновации, в общем числе обследованных организаций }\end{array}$ & процент \\
\hline$x_{10}$ & $\begin{array}{l}\text { Доля инновационных товаров, работ, услуг в общем объеме отгруженных товаров, } \\
\text { выполненных работ, услуг организаций промышленного производства и сферы } \\
\text { услуг }\end{array}$ & процент \\
\hline$x_{11}$ & $\begin{array}{l}\text { Доля инновационных товаров, работ, услуг в общем объеме экспорта товаров, вы- } \\
\text { полненных работ, услуг организаций промышленного производства и сферы услуг }\end{array}$ & процент \\
\hline$x_{12}$ & $\begin{array}{l}\text { Удельный вес принципиально новых технологий, в общем числе разработанных } \\
\text { передовых производственных технологий }\end{array}$ & процент \\
\hline \multicolumn{3}{|c|}{$\begin{array}{c}\text { Субиндекс } 3 \text { «Инфраструктура информационно-коммуникационных технологий } \\
\text { и доступность информационных технологий для развития» }\end{array}$} \\
\hline$x_{13}$ & Телефонная плотность фиксированной связи на 100 человек населения & единиц \\
\hline$x_{14}$ & Проникновение подвижной радиотелефонной связи на 100 человек населения & единиц \\
\hline$x_{15}$ & $\begin{array}{l}\text { Число пунктов коллективного пользования, имеющих выход в сеть Интернет на } \\
10000 \text { человек }\end{array}$ & единиц \\
\hline$x_{16}$ & $\begin{array}{l}\text { Число абонентов фиксированного широкополосного доступа в Интернет на } 100 \\
\text { человек населения }\end{array}$ & абонент \\
\hline$x_{17}$ & $\begin{array}{l}\text { Число абонентов мобильного широкополосного доступа в Интернет на } 100 \text { человек } \\
\text { населения }\end{array}$ & абонент \\
\hline$x_{18}$ & Уровень цифровизации местной телефонной сети & процент \\
\hline$x_{19}$ & $\begin{array}{l}\text { Удельный вес телефонизированных населенных пунктов в сельской местности в } \\
\text { общем числе сельских населенных пунктов }\end{array}$ & процент \\
\hline$x_{20}$ & $\begin{array}{l}\text { Тариф на предоставление абоненту в постоянное пользование абонентской линии } \\
\text { независимо от ее типа, месяц }\end{array}$ & Усл. ед \\
\hline$x_{21}$ & Абонентская плата за доступ к сети Интернет, месяц & Усл. ед. \\
\hline$x_{22}$ & Предоставление местного соединения по сотовой связи, минута & Усл. ед. \\
\hline$x_{23}$ & $\begin{array}{l}\text { Тариф за одну минуту местного телефонного соединения при повременной систе- } \\
\text { ме оплаты, минута }\end{array}$ & Усл. ед. \\
\hline
\end{tabular}




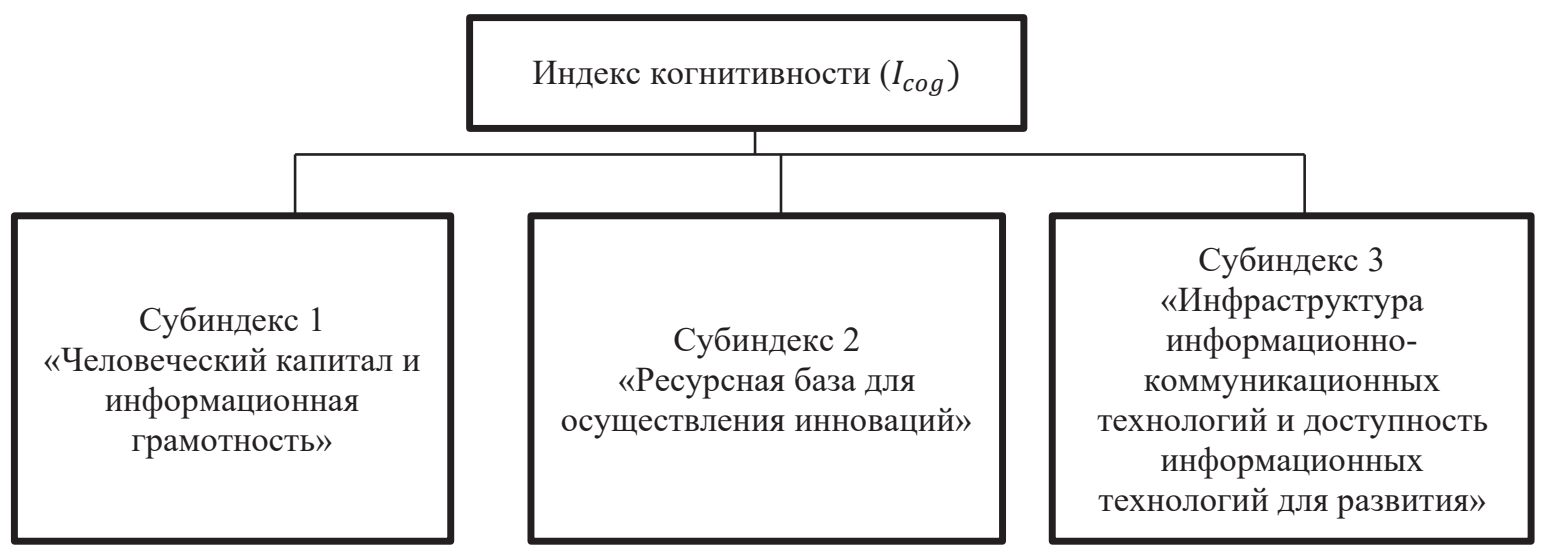

Рисунок 3. Структура индекса когнитивности

числены матрицы произведений:

$$
W_{k}=X_{k} X_{k}^{T}
$$

где $X_{k}$ - матрица нормализованных значений, а $X_{k}^{T}$ - транспонированная матрица нормализованных значений.

Затем определено

$$
\begin{aligned}
& \left\langle W_{k}, W_{k^{\prime}}\right\rangle_{H-S}=\operatorname{trace}\left(W_{k}^{T} W_{k^{\prime}}\right) \\
& \text { - произведение Гильберта-Шмидта. }
\end{aligned}
$$

Сформирована корреляционная матрица, элементами которой являются коэффициенты корреляции:

$$
R V_{k, k^{\prime}}=\frac{\operatorname{trace}\left(W_{k}^{T} W_{k^{\prime}}\right)}{\sqrt{\operatorname{trace}\left(W_{k}^{T} W_{k}\right) \cdot \operatorname{trace}\left(W_{k^{\prime}}^{T} W_{k^{\prime}}\right)}}
$$

Были получены наборы весов $\left(a_{k}\right)$ от собственных векторов.

Затем вычислена компромиссная матрица в виде линейной комбинации

$$
W=\sum_{k=1}^{K} a_{k} W_{k}
$$

По таблицам квадратов косинусов были построены таблицы значений вкладов факторов в главные компоненты. Для каждой компоненты переменные с вкладом, превышающим 10\%, рассматривалась как важная для внесения вклада в данный компонент, так как, если бы вклад переменных был равномерным, то ожидаемое значение было бы равно 1/10 = 10\%. Были построены таблицы распределения весов всех факторов и таблицы распределения весов факторов, которые входят в главные компоненты. И затем рассчитаны веса для субиндексов. Далее была составлена таблица распределения весов (табл. 4).

Таким образом, суммарные вклады, входящие в главные компоненты, изменяются от 89,89 (Россия) до 96,81 (Китай). Значения суммарных вкладов Индии и ЮАР выше среднего, Бразилии - ниже. Веса для субиндекса 1 изменяются от 62 (Россия) до 84 (Китай). Значения весов первого субиндекса в Бразилии и Индии выше среднего, в ЮАР - ниже. Веса для субиндекса 2 изменяются от 8 (Китай) до 26 (Россия). Значение веса для второго субиндекса в ЮАР выше среднего, в Бразилии и Индии - ниже. Веса для субиндекса 3 изменяются от 8 (Китай) до 12 (Россия). Значение веса третьего субиндекса Бразилии выше среднего, Индии и ЮАР - ниже. На основе представленной методологии рассчитан индекс когнитивности в странах БРИКС (Таблица 5).

Расчеты показали, что по индексу когнитивности на 2020 год лидером является Китай $(0,76)$, Россия находится на втором месте $(0,56)$.

Таким образом, исследование проблем, связанных с качественной трансформации технологической базы мировой экономики, приобретает все большее значение [5, 11]. В условиях современного общества идет конкуренция как за кадры, так и за научно-технические разработки, создаваемые ими. Однако, исследования в этой области далеки от завершения. Представленные инструменты оценки интеллектуализации экономики охватывают лишь отдельные сферы когнитивной экономики.

Разработанный индекс когнитивности включает в себя все принципиально важные процессы когнитивной экономики такие как 
Таблица 4. Распределение весов

\begin{tabular}{|c|c|c|c|c|c|c|c|}
\hline \multirow{2}{*}{ Страна } & \multicolumn{3}{|c|}{ Распределение весов } & \multirow{2}{*}{$\begin{array}{c}\text { Суммарный } \\
\text { вклад }\end{array}$} & \multicolumn{3}{|c|}{ Веса для субиндексов } \\
\hline & pc1 & pc2 & pc3 & & pc1 & pc2 & pc3 \\
\hline Россия & 91,32 & 79,25 & 6,6 & 89,89 & 62 & 26 & 12 \\
\hline Бразилия & 95,20 & 66,54 & 30,54 & 92,93 & 77 & 13 & 10 \\
\hline Индия & 98,63 & 62,30 & 37,15 & 94,26 & 80 & 11 & 9 \\
\hline Китай & 99,34 & 37,51 & 43,67 & 96,81 & 84 & 8 & 8 \\
\hline ЮАР & 98,43 & 74,74 & 56,59 & 94,21 & 72 & 19 & 9 \\
\hline
\end{tabular}

Источник: составлено авторами.

Таблица 5. Значения индекса когнитивности стран БРИКС

\begin{tabular}{|l|c|c|c|c|c|c|c|c|c|c|c|}
\hline \multicolumn{1}{|c|}{ Страна } & 2010 & 2011 & 2012 & 2013 & 2014 & 2015 & 2016 & 2017 & 2018 & 2019 & 2020 \\
\hline Россия & $-0,05$ & $-0,06$ & $-0,06$ & 0,03 & 0,07 & 0,1 & 0,04 & 0,16 & 0,55 & 0,55 & 0,56 \\
\hline Бразилия & $-0,04$ & $-0,03$ & $-0,02$ & 0,14 & 0,12 & 0,13 & 0,22 & 0,16 & 0,3 & 0,38 & 0,47 \\
\hline Индия & $-0,06$ & $-0,08$ & $-0,01$ & 0,05 & 0,11 & 0,19 & 0,21 & 0,3 & 0,41 & 0,48 & 0,44 \\
\hline Китай & 0,01 & 0,05 & 0,21 & 0,38 & 0,47 & 0,44 & 0,77 & 0,61 & 0,74 & 0,71 & 0,76 \\
\hline ЮАР & $-0,01$ & $-0,03$ & $-0,08$ & 0,02 & 0,12 & 0,17 & 0,19 & 0,14 & 0,24 & 0,34 & 0,46 \\
\hline
\end{tabular}

человеческий капитал и информационная грамотность, ресурсная база для осуществления инноваций и инфраструктура информационнокоммуникационных технологий и доступность информационных технологий для развития. Он рассчитывался методом обобщенных главных компонент по методологии STATIS.

Уровень интеллектуализации становится фактором, определяющим социальную дифференциацию. В результате все чаще выявляется зависимость экономического развития стран от качества интеллектуальных ресурсов, которыми они обладают. Таким образом, обществу нужны показатели, которые выявляют изменения, влияющие на долгосрочное экономическое развитие. Использование разработанного индекса когнитивности позволит проводить анализ когнитивной экономики, следить за ее динамикой и выявлять имеющие наибольшее значение процессы.

\section{Библиографический список}

1. Архипова М.Ю., Сиротин В.П., Сухарева Н.А. Разработка композитного индикатора для измерения величины и динамики цифрового неравенства в РФ // Вопросы статистики. 2018 № 4. С.75-87. Т.25

2. База данных ОЭСР [Электронный ресурс]. - URL: https://data.oecd.org/ (дата обращения 26.06.2020).

3. Зурабян А. С. Инновационная активность промышленных предприятий и механизмы ее стимулирования / А. С. Зурабян // ТДР. 2016 № 6. С. 27-29.

4. Игнатов А.А. (2020) Цифровая экономика в БРИКС: перспективы многостороннего сотрудничества // Вестник международных организаций. Т. 15. № 1.С. 31-62.

5. Карлик А.Е. Исследование инновационного развития предприятий: проблемы и тенденции / А.Е. Карлик, В. В. Платонов // Стратегии бизнеса. 2016 № 7 (27). С. 13-16.

6. Национальная служба статистики Бразилии [Электронный ресурс].- URL: https://www.ibge.gov.br/ (дата обращения 25.10.2020).

7. Национальная служба статистики Индии [Электронный ресурс].- URL: http://mospi.gov.in/ (дата обращения 25.10.2020).

8. Национальная служба статистики Китая [Электронный ресурс]. - URL: http://www.stats.gov.cn/ (дата обращения 25.10.2020).

9. Национальная служба статистики ЮАР [Электронный ресурс]. - URL: http://www.statssa.gov.za/ (дата обращения 25.10.2020). 
10. Сафиуллин А.Р. Интеллектуализация современной экономики: опыт стран организации экономического сотрудничества и развития / А.Р. Сафиуллин // Экономический анализ: теория и практика. 2012. № 5 . С. 56-60.

11. Стратегия интенсивного инновационного развития России на основе развития и использования человеческого капитала / под ред. Ю.Н. Макарова. М.: РУДН, 2015. 478 с.

12. Хадькова Л.Т. Проблема интеллектуализации в экономике / Л. Т. Хадькова // Экономические науки. 2017. № 5 (150). C. 11-13.

13. Fumagalli, A., Lucarelli, S. A model of cognitive capitalism. A preliminary analysis // European journal of economic and social systems, 2007. № 20(1), 117-133.

14. Fumagalli, A., Lucarelli, S. Cognitive capitalism as a financial economy of production // Munich personal RePEc archive. 2008 Режим доступа: mpra.ub.uni-muenchen.de/27989. (дата обращения 04.11.2020)

15. Lavit, C., Escoufier, Y., Sabatier, R., Traissac, P. (The ACT (STATIS method) // Computational Statistics \& Data Analysis. 1994. Vol. 18. Issue 1. P. 97-119.

16. Main Science and Technology Indicators, Volume 2019 Issue 2 / OECD Publishing, Paris, 2020 